\title{
SISTEM PAKAR DETEKSI KERUSAKAN MESIN DIESEL PLTD MENGGUNAKAN METODE FORWARD CHAINING
}

\author{
Frilian Amanda Nurhaya ${ }^{1}$, Ely Setyo Astuti² \\ Program Studi Teknik Informatika, Jurusan Teknologi Informasi, Politeknik Negeri Malang \\ 다ilian.amanda@gmail.com, ${ }^{2}$ nugelys2005@yahoo.com
}

\begin{abstract}
Abstrak
Mesin diesel pembangkit listrik tenaga diesel dapat mengalami kerusakan pada komponen-komponennya, kerusakan tersebut dapat diketahui melalui ciri-ciri kerusakan yang ditimbulkan oleh mesin tersebut. Akan tetapi untuk melakukan suatu tindakan yang tepat diperlukan seorang ahli / pakar mesin diesel pembangkit listrik tenaga diesel yang dapat mengetahui dengan tepat tindakan yang akan dilakukan untuk mengatasi kerusakan tersebut. Banyaknya ciri-ciri kerusakan yang ditimbulkan dari kerusakan mesin diesel PLTD, maka diperlukan suatu sistem pakar yang dapat membantu teknisi untuk mendeteksi kerusakan mesin diesel PLTD. Pada penelitian ini dirancang sistem pakar berbasis desktop menggunakan dasar aturan (rule based reasoning) dengan metode forward chaining. Metode forward chaining merupakan metode pencarian maju yang dimaksudkan dapat membantu teknisi dalam mendeteksi kerusakan mesin diesel pltd dan juga digunakan untuk meringankan tugas seorang pakar(supervisor). Penelitian ini mengambil data di PLTD Poasia, Sulawesi Tenggara.
\end{abstract}

Kata kunci : forward chaining, rule based reasoning, mesin diesel PLTD

\section{Pendahuluan}

Pembangkit Listrik Tenaga Diesel sebagai salah satu pembangkit listrik yang dimiliki oleh Perusahaan Listrik Negara menggunakan mesin diesel sebagai mesin penggerak sumber daya listrik. Mesin diesel merupakan mesin panas yang didalarnnya terdapat energi kimia dari pembakaran yang dilepaskan ke dalam silinder mesin.

Standar perawatan dan pemeliharaan mesin diesel harus diperhatikan. Seluruh teknisi harus memiliki keahlian dalam hal perawatan dan pemeliharaan mesin diesel. Keahlian tersebut bisa diperoleh dari pelatihan resmi yang dilakukan oleh perusahaan, membaca buku panduan mengatasi kerusakan mesin yang didapat dari pabrik pembuat mesin diesel dan ilmu pengetahuan tambahan yang didapat dari pembelajaran selama di lembaga pendidikan. Ketika mesin mengalami kerusakan teknisi melakukan perbaikan sesuai dengan persetujuan supervisior.

Ketika terjadi gangguan pada mesin diesel teknisi harus bekerja cepat untuk mengidentifikasi ciri-ciri kerusakan mesin diesel dan berkomunikasi dengan teknisi lain lalu mengkonsultasikan kepada supervisior sebelum mengambil tindakan yang tepat. Dengan adanya sistem pakar yang mendeteksi kerusakan mesin diharapkan dapat membantu kinerja teknisi dan supervisior.

Sebelumnya sudah dilakukan penelitian tentang sistem pakar kerusakan mesin diesel lokomotif yang menggunakan metode runut maju (forward chaining) oleh Citra Kusumawati dari STMIK Yogyakarta pada tahun 2011. Penelitian tersebut berisikan list keadaan mesin diesel yang sedang dialami pada saat melakukan konsultasi lalu diolah melalui proses penentuan solusi sehingga dapat diperoleh solusinya

Dalam hal ini diperlukan juga sistem yang dapat membantu teknisi PLTD dalam melakukan tugas perawatan dan perbaikan mesin diesel. Dimana dengan data keadaan mesin diesel yang diperoleh kemudian diolah melalui proses dan ditemukan solusi tindakan yang harus diambil. Oleh karena itu dalam penelitian ini penulis akan merancang dan membuat sebuah sistem pakar yang dapat mendeteksi ciri-ciri kerusakan mesin diesel dan memberikan tindakan yang harus diambil dengan menggunakan metode forward chaining. Forward chaining sendiri merupakan metode sistem pakar yang menggunakan data sebagai aturan yang mana akan dijalankan.

\section{Sistem Pakar}

Sistem Pakar (expert system) secara umum adalah sistem yang berusaha mengadopsi pengetahuan manusia ke komputer, agar komputer dapat menyelesaikan masalah seperti yang biasa dilakukan oleh para ahli. Sistem pakar juga bisa dikaitkan sebagai sistem yang didesain dan diimplementasikan dengan bantuan bahasa pemograman tertentu. Tujuannya untuk dapat menyelesaikan masalah seperti yang dilakukan oleh para ahli. Sistem pakar membantu orang awam untuk dapat menyelesaikan masalah yang cukup rumit yang sebenarnya hanya dapat diselesaikan dengan bantuan para ahli. Bagi para ahli, sistem pakar ini juga akan membantu 
aktivitasnya sebagai asisten yang sangat berpengalaman.

1. Karakteristik Sistem Pakar

Giaratano dan riley menyatakan bahwa sistem pakar di desain untuk memiliki beberapa karakteristik berikut ini :

- High performance

Sistem diharapkan mampu untuk merespon dengan kompetensi sebanding dengan yang dimiliki dengan yang dimiliki oleh seorang ahli atau pakar. Maka dari itu kualitas penyelesaian masalah yang diberikan diharuskan sangat tinggi.

- Adequate response time

Sistem harus dapat bekerja dengan waktu yang masuk akal, dapat dibandingkan atau lebih baik dari waktu yang dibutuhkan oleh seorang ahli atau pakar dalam menyelesaikan suatu permasalahan

- Good Reliability

Suatu sistem pakar harus dapat diandalkan dan tidak mudah crash.

- Understandable

Sistem pakar harus dapat menjelaskan langkah-langkah penalaran yang dilakukan. Sistem harus memiliki fasilitas penjelas untuk menjelaskan penalaran yang dilakukan seperti seorang ahli atau pakar melakukan penalaran Publishing House.

\section{Mesin Diesel PLTD}

Mesin diesel merupakan jenis khusus dari mesin pembakaran dalam. Sesuai dengan namanya, mesin pembakaran dalam adalah mesin panas yang di dalamnya, energi kimia dari pembakaran dilepaskan di dalam silinder mesin, sedangkan golongan lain dari mesin panas, mesin uap, energi yang ditimbulkan selama pemabakaran bahan bakar diteruskan lebih dahulu ke uap dan hanya ditimbulkan selama pembakaran bahan bakar diteruskan lebih dahulu ke uap dan hanya melalui uap uaplah kerja dilakukan dalam mesin atau turbin. Tetapi, karena tidak ada mesin dngan pemabakaran luar, kecuali pengembangan yang terkahir, yaitu turbin gas, yang dalam segala hal berada dalam satu kelompok dengan sendirinya, maka pada saat ini terdapat kecenderungan untuk menyebutkan semua mesin panas yang dioperasikan langsung oleh gas. Pembakaran adalah secara sederhana mesin pembakaran (motor bakar). Nama yang pendek ini akan digunakan dalam reks selanjutnya.

Terdapat beberapa alasan mengapa mesin diesel tidak hanya menyaingi mesin panas yang lain tetapi dalam banyak hal menguasai medan. Kelas pelayannya adalah faktor utama dalam banyak kasus. Salah satu penggunaan yang menonjol dari mesin diesel adalah transportasi, di darat dan di air, pada truk, kereta rel, lokomotif, perahu dan kapal. Dalam banyak instalasi ukuran kecil dan sedang, pada pertanian dan perusahaan industri kecil, maka kesederhanaan dari biaya rendah dari operasi menetukan bahwa pemakaian mesin minyak lebih disukai daipada mesin uap atau motor listrik. Dalam instalasi daya besar, yang digunakan untuk menghasilkan arus listrik atau penggerakan kapal, maka penghematan bahan bakar menentukan ipilihan pada mesin diesel.

\section{Metode Forward Chaining}

Forward chaining adalah metode pencarian atau penarikan kesimpulan yang berdasarkan pada data atau fakta yang ada menuju kesimpulan, penulusuran dimulai dari fakta yang ada lalu bergerak maju melalui premis-premis untuk menuju ke kesimpulan atau bottom up reasoning. Forward chaining melakukan pencarian dari suatu masalah kepada solusinya.

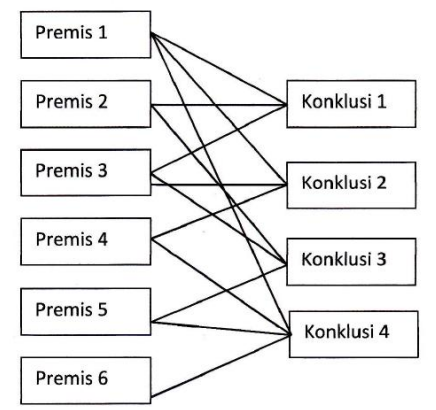

Gambar 1. Alur Forward Chaining

Berikut merupakan penjelasan dari gambar diatas : Premis 1, Premis 2, Premis 3, Premis 4, Premis 5 dan Premis 6 di dalam sistem yang akan penulis bangun menggunakan metode forward chaining merupakan ciri-ciri kerusakan mesin diesel. Dimana dari ciri-ciri kerusakan mesin diesel tersebut akan keluar konklusi. Konklusi disini merupakan tindakan atau solusi penanganan kerusakan mesin diesel.

Dari gambar diatas dapat dijelaskan bahwa :

- Konklusi 1 dapat dilakukan apabila Premis 3 terpenuhi.

- Konklusi 2 dapat dilakukan apabila Premis 1, Premis 3 dan Premis 4 terpenuhi

- Konklusi 3 dapat dilakukan apabila Premis 2, Premis 3 dan Premis 5 terpenuhi.

- Konklusi 4 dapat dilakukan apabila Premis 1, Premis 4, Premis 5 dan Premis 6 terpenuhi.

\section{Basis Pengetahuan}

Basis pengetehauan memiliki tujuan untuk meningkatkan pengetahuan dalam sistem pakar. Sistem pakar ini memerlukan pengetahuan berupa data ciri-ciri kerusakan mesin diesel, data tindakan yang harus dilakukan dan prosentase kemungkinan tindakannya. 
Tabel 1. Basis Pengetahuan

\begin{tabular}{|c|c|c|}
\hline $\begin{array}{l}\text { kode_ti } \\
\text { ndakan }\end{array}$ & nama_ciri & $\begin{array}{l}\text { Prosentase } \\
\text { Tindakan }\end{array}$ \\
\hline T001 & $\begin{array}{l}\text { IF Apakah Press J/W } \\
\text { hunting dari } 2.5-29 \\
\text { bar (Injeksi } 70 \% \text { ? } \\
\text { OR Apakah Asap } \\
\text { Dari Extraction Fan } \\
\text { kemasukan air? OR } \\
\text { Apakah kebocoran air } \\
\text { pendingin antara cyl } \\
\text { head B1-B2 } \\
\text { bertambah besar? OR } \\
\text { Apakah JW Press } \\
\text { Trip pada saat blow } \\
\text { off keluar air pada cyl. } \\
\text { bank A6? OR Apakah } \\
\text { Ada kebocoran air } \\
\text { pendingin antara Cyl. } \\
\text { Head A3 - A4? OR } \\
\text { Apakah pada saat } \\
\text { blow off ada kleuar } \\
\text { air Valve Indicator } \\
\text { Cock A4, A5? OR } \\
\text { Apakah ada Indikasi } \\
\text { kebocoran Air antara } \\
\text { Cyl Head B1/B2, } \\
\text { B3/B4, A1/A2? }\end{array}$ & 14,2857 \\
\hline T003 & $\begin{array}{l}\text { Apakah 1 Trip ( } \mathrm{J} / \mathrm{W} \\
\text { Press Trip) blow off } \\
\text { ada kandungan air } \\
\text { yang keluar dari cly } \\
\text { B.8? }\end{array}$ & 100 \\
\hline T004 & $\begin{array}{l}\text { Apakah Press J/W trip } \\
2 \mathrm{x} \text { (saat blow off ada } \\
\text { air di Bank B8? OR } \\
\text { Apakah Pressure J/W } \\
\text { hunting dari 2.2-1.9 } \\
\text { bar, injeksi } 10 \% \text { ? }\end{array}$ & 50 \\
\hline
\end{tabular}

\section{Perhitungan Prosentase Kemungkinan Tindakan}

Perhitungan prosentase kemungkinan tindakan dilakukan dengan memilih beberapa ciri kerusakan yang sama tindakannya. Kemudian ciri yang memiliki tindakan sama akan dijumlahkan dan keluar hasil prosentase kemungkinan tindakan yang harus dilakukan untuk ciri-ciri yang telah dipilh. Berikut merupakan perhitungan manual dari sistem pakar deteksi kerusakan meisn PLTD menggunakan metode forward chaining :
Tabel 2. Ciri-ciri kerusakan dan Tindakan

\begin{tabular}{|c|c|}
\hline Kode tindakan & Nama Ciri \\
\hline \multirow{7}{*}{ Т001 } & $\begin{array}{l}\text { Apakah Press J/W hunting } \\
\text { dari } 2.5-29 \text { bar (Injeksi } 70 \%) ?\end{array}$ \\
\hline & $\begin{array}{l}\text { Apakah Asap Dari Extraction } \\
\text { Fan kemasukan air? }\end{array}$ \\
\hline & $\begin{array}{l}\text { OR Apakah kebocoran air } \\
\text { pendingin antara cyl head B1- } \\
\text { B2 bertambah besar? }\end{array}$ \\
\hline & $\begin{array}{l}\text { Apakah JW Press Trip pada } \\
\text { saat blow off keluar air pada } \\
\text { cyl. bank A6? }\end{array}$ \\
\hline & $\begin{array}{l}\text { Apakah Ada kebocoran air } \\
\text { pendingin antara Cyl. Head A3 } \\
\text { - A4? }\end{array}$ \\
\hline & $\begin{array}{l}\text { Apakah pada saat blow off ada } \\
\text { kleuar air Valve Indicator } \\
\text { Cock A4, A5? }\end{array}$ \\
\hline & $\begin{array}{l}\text { Apakah ada Indikasi kebocoran } \\
\text { Air antara Cyl Head B1/B2, } \\
\text { B3/B4, A1/A2? }\end{array}$ \\
\hline T002 & $\begin{array}{l}\text { Apakah ada kebocoran air di } \\
\text { Liner A5. B5.7 sisi luar dan } \\
\text { yang besar keluar airnya B7 + } \\
\text { Blow Off normal? }\end{array}$ \\
\hline T003 & $\begin{array}{l}\text { Apakah } 1 \text { Trip (J/W Press Trip) } \\
\text { blow off ada kandungan air } \\
\text { yang keluar dari cly B.8? }\end{array}$ \\
\hline \multirow[t]{2}{*}{ T024 } & $\begin{array}{l}\text { Apakah Indikasi hunting temp. } \\
\text { Bank A3, A6, B7 secara } \\
\text { continue, A3 514-512 }{ }^{\circ} \mathrm{C} \text {, A6 } \\
483-492^{\circ} \mathrm{C}, \mathrm{B} 7487-508^{\circ} \mathrm{C} . ?\end{array}$ \\
\hline & $\begin{array}{l}\text { Apakah pada saat } \mathrm{C} / \mathrm{O} \text { L.O } \\
\text { filter ada gram - gram pada } \\
\text { filter sisi bawah DP } 0.8 \text { bar? }\end{array}$ \\
\hline T034 & $\begin{array}{l}\text { Apakah suara ketukan Cyl } \\
\text { Head A4 kasar dibanding } \\
\text { bank yang lain? }\end{array}$ \\
\hline
\end{tabular}

Tabel 3. Perhitungan Manual Awal

\begin{tabular}{|c|c|c|}
\hline $\begin{array}{l}\text { Kode } \\
\text { Tindakan }\end{array}$ & $\begin{array}{l}\text { Jumlah } \\
\text { Ciri }\end{array}$ & $\begin{array}{l}\text { Prosentase } \\
\text { Kemungkinan } \\
\text { Tindakan Tiap Ciri }\end{array}$ \\
\hline T001 & 7 & 14,2857 \\
\hline T002 & 1 & 100 \\
\hline T024 & 2 & 100 \\
\hline
\end{tabular}

Keterangan :

Jumlah ciri $=$ jumlah ciri dalam satu tindakan

Prosentase kemungkinan tindakan tiap ciri $=$ nilai untuk setiap ciri 
Tabel 4. Perhitungan Manual Akhir

\begin{tabular}{|c|c|c|}
\hline $\begin{array}{l}\text { Kode } \\
\text { Tindakan }\end{array}$ & $\begin{array}{l}\text { Jumlah } \\
\text { Ciri } \\
\text { Terpenuhi }\end{array}$ & $\begin{array}{l}\text { Prosentase } \\
\text { kemungkinan dari } \\
\text { keseluruhan }\end{array}$ \\
\hline T001 & 2 & $\begin{array}{c}14,2857+14,2857= \\
28,5714\end{array}$ \\
\hline T002 & 1 & 100 \\
\hline T024 & 2 & $50+50=100$ \\
\hline
\end{tabular}

Keterangan :

Jumlah ciri terpenuhi $=$ jumlah ciri yang dipilih

Prosentase kemungkinan dari keseluruhan $=$ total kemungkinan tindakan yang dilakukan.

\section{Antar Muka}

Antar muka atau user interface yang digunakan dalam sistem pakar deteksi kerusakan mesin diesel pltd ini dibuat denan sederhana, karena sistem pakar ini berbabis destkop sehingga template yang digunakan merupakan template yang sesuai dengan tampilan destkop.

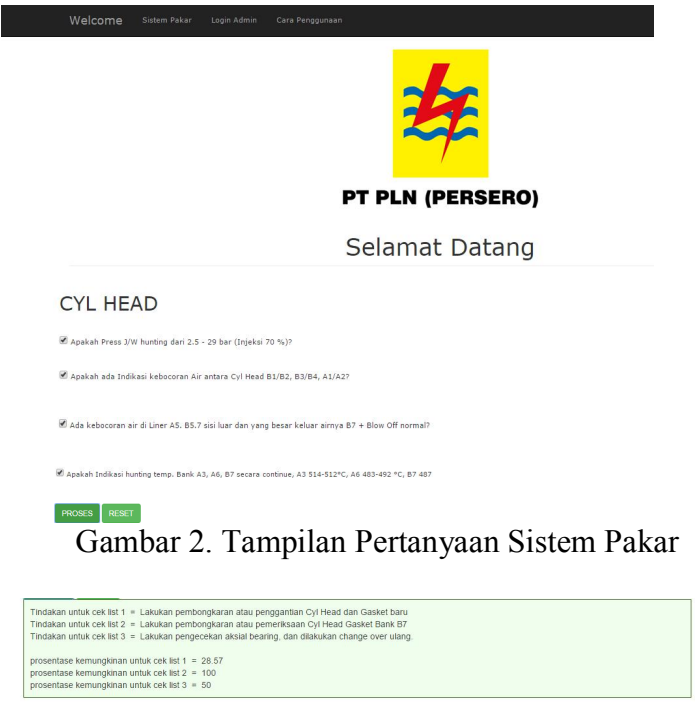

Gambar 3. Tampilan Jawaban Tindakan

\section{Pengujian}

Pengujian merupakan cara atau teknik untuk menguji perangkat lunak, mempunyai mekanisme untuk menentukan data uji yang dapat menguji perangkat lunak secara lengkap dan mempunyai kemungkinan tinggi untuk menemukan kesalahan.Berikut dibawah merupakan pengujian yang dilakukan di dalam sistem pakar deteksi kerusakan mesin diesel pltd.

- Pengujian Blackbox

Pengujian ini dilakukan untuk menemukan fungsi-fungsi yang tidak benar atau hilang, kesalahan interface, kesalahan dalam struktur data atau akses database eksternal, kesalahan kinerja, inisialisasi dan kesalahan terminasi. Pengujian fungsi-fungsi pada sistem pakar deteksi kerusakan mesin diesel PLTD telah berjalan dengan baik. Sistem pakar dapat memproses ciri-ciri kerusakan hingga dimunculkan tindakan dan prosentase kemungkina untuk tindakan. Berikut hasil scenario pengujian fungsional pada table 5.1.

Tabel 5. Skenario hasil pengujian

\begin{tabular}{|l|l|}
\hline Fungsionalitas & Selesai \\
\hline $\begin{array}{l}\text { Fungsi-fungsi pada } \\
\text { website }\end{array}$ & $\sqrt{ }$ \\
\hline
\end{tabular}

\section{- Pengujian Whitebox}

Pengujian ini dilakukan untuk menilai apakah perangkat lunak yang dikembangkan telah memenuhi kebutuhan pemakai dan menilai apakah tahap pengembangan perangkat lunak telah sesuai dengan metodologi yang digunakan.

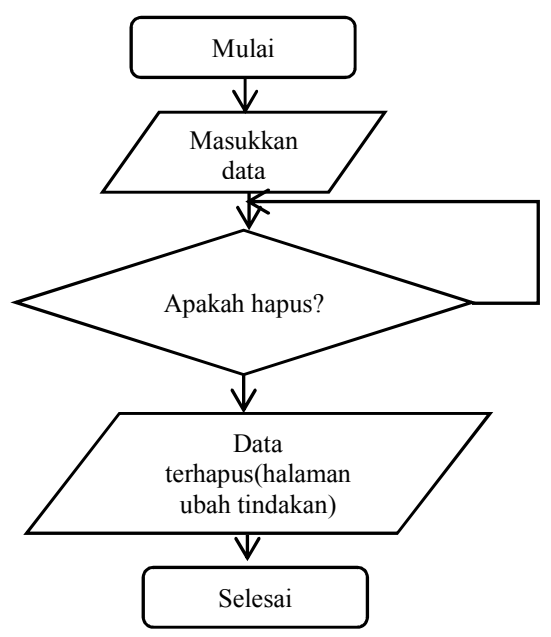

Gambar 4. Alur hapus tindakan

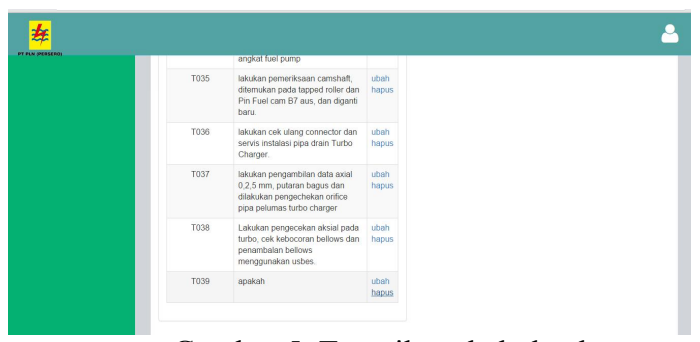

Gambar 5. Tampilan ubah dan hapus tindakan 


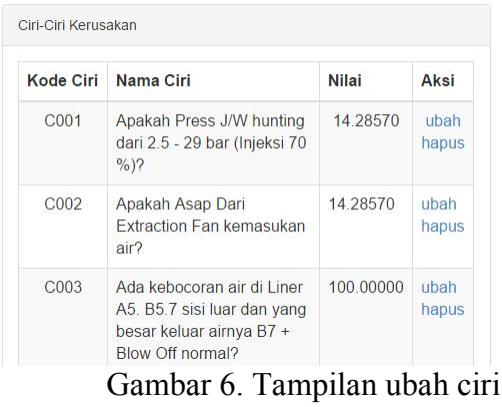

Dari 2 gambar diatas yakni gambar 4 dan gambar 5 pengujian dilakukan kemudian menghasilkan ketidak sesuaian antara rancangan dikarenakan tombol hapus yang seharusnya kembali ke menu ubah tindakan menjadi ke menu ubah ciri.

\section{Kesimpulan}

Kesimpulan dari laporan skripsi sistem pakar deteksi kerusakan mesin diesel pltd menggunakn forward chaining ini adalah :

- Input dari sistem merupakan ciri-ciri kerusakan sedangkan outputnya adalah tindakan dan prosentase kemungkinan tindakan.

- Semakin banyak ciri-ciri yang dipilih dalam satu tindakan. Maka prosentase kemungkinan tindakan yang diperoleh juga semakin besar.

- Uji coba sesuai dengan nilai perhitungan manual.

\section{Saran}

Saran dari penulis sistem ini untuk penelitian kedepannya.

- $\quad$ Sistem ini perlu dijadikan aplikasi berbasis android mengetahui di era global ini semua teknologi sudah semakin canggih. Sehingga kebanyakan orang memakai handphone sebagai media untuk melakukan kegiatan pekerjaan merekanya, terutama yang berbasis android sekarang ini.

- Memakai metode perhitungan lainya agar lebih akurat untuk contoh perhitungan satu tindakan dengan satu ciri.

\section{Daftar Pustaka}

Akhmad,E.P.A.Pengembangan Sistem Pakar untuk diagnosis kerusakan mesin diesel.Jurnal Ilmiah Universitas Hang Tuah. 1-16

Giaratno, J dan Riley, G . 2002. Expert System Priciplies and Programming, third edition. China: China Machine Press dan CITIC

Honggowibowo,S. A. Sistem Pakar Diagnosa Penyakit Tanaman Padi berbasis web dengan metode forward chaining dan backward chaining.Jurnal Ilmiah Sekolah Tinggi Teknologi Adisutjipto.187-194

Kusrini. 2006. Sistem Pakar Teori dan Aplikasi.Yogyakarta: C.V. Andi Offset . 2008. Aplikasi Sistem Pakar menetukan Faktor Kepastian Pengguna dengan Metode kuantifikasi Pertanyaan. Yogyakarta: C.V. Andi Offset

Kusumawati, C. 2011. Sistem Pakar untuk Deteksi Kerusakan Mesin Lokomotif Diesel Pada Kereta Api. Jurnal Ilmiah STMIK AMIKOM.1-19

Rouf, A. Pengujian perangkat lunak dengan menggunakan metode white box dan black box. Jurnal Ilmiah STMIK HIMSYA, 2-7

Yuniarto, A., et all. 2012. Modul Ajar Motor Bakar II. Malang: Politeknik Negeri Malang

Yuwono, B. 2010. Pengembangan Sistem Pakar Pada Perangkat Mobile untuk mendiagnosa Penyakit Gigi. Yogyakarta: Seminar Nasional Informatika UPN Veteran 